\title{
Spatial variability in intertidal macroalgal assemblages on the North Portuguese coast: consistence between species and functional group approaches
}

\author{
P. Veiga $\cdot$ M. Rubal $\cdot$ R. Vieira $\cdot$ F. Arenas $\cdot$ \\ I. Sousa-Pinto
}

Received: 14 December 2011/Revised: 13 June 2012/Accepted: 21 June 2012/Published online: 6 July 2012

(C) Springer-Verlag and AWI 2012

\begin{abstract}
Natural assemblages are variable in space and time; therefore, quantification of their variability is imperative to identify relevant scales for investigating natural or anthropogenic processes shaping these assemblages. We studied the variability of intertidal macroalgal assemblages on the North Portuguese coast, considering three spatial scales (from metres to $10 \mathrm{~s}$ of kilometres) following a hierarchical design. We tested the hypotheses that (1) spatial pattern will be invariant at all the studied scales and (2) spatial variability of macroalgal assemblages obtained by using species will be consistent with that obtained using functional groups. This was done considering as univariate variables: total biomass and number of taxa as well as biomass of the most important species and functional groups and as multivariate variables the structure of macroalgal assemblages, both considering species and functional groups. Most of the univariate results confirmed the first hypothesis except for the total number of taxa and foliose macroalgae that showed significant variability at the scale of site and area, respectively. In contrast, when multivariate patterns were examined, the first hypothesis was rejected except at the scale of $10 \mathrm{~s}$ of kilometres. Both uni- and multivariate results indicated that
\end{abstract}

Communicated by Inka Bartsch.

P. Veiga $(\bowtie) \cdot$ M. Rubal $\cdot$ R. Vieira $\cdot$ F. Arenas .

I. Sousa-Pinto

Laboratory of Coastal Biodiversity, Centre of Marine and Environmental Research (CIIMAR), University of Porto, Rua dos Bragas 289, 4050-123 Porto, Portugal

e-mail: puri.veiga@hotmail.com

I. Sousa-Pinto

Department of Biology, Faculty of Sciences, University of Porto, Rua do Campo Alegre s/n, 4150-181 Porto, Portugal variation was larger at the smallest scale, and thus, smallscale processes seem to have more effect on spatial variability patterns. Macroalgal assemblages, both considering species and functional groups as surrogate, showed consistent spatial patterns, and therefore, the second hypothesis was confirmed. Consequently, functional groups may be considered a reliable biological surrogate to study changes on macroalgal assemblages at least along the investigated Portuguese coastline.

Keywords Spatial variability · Macroalgal assemblages . Functional groups - Hierarchical analysis .

Rocky intertidal $\cdot$ North Portugal

\section{Introduction}

Natural assemblages are complex and intrinsically variable in space and time. Populations' density is more variable at some spatial and temporal scales than at others, and thus, changes in the composition and structure of assemblages are more evident at particular scales (Benedetti-Cecchi 2001). This natural variability is commonly considered as a difficulty to understand ecological processes, but there is an increasing appreciation that more knowledge about this variability is crucial to understand the ecological processes structuring natural systems (Martins et al. 2008).

The quantification of assemblages' natural variability is imperative in order to identify relevant scales for investigating either natural processes or anthropogenic impacts on ecological systems (Anderson et al. 2005b). Different environmental and biological processes responsible for shaping assemblage structure act at different temporal and spatial scales. Therefore, analysis of spatial patterns of assemblages contributes to identify the major ecological 
processes that may determine these patterns (Underwood and Chapman 1996; Burrows et al. 2009). Consequently, describing pattern studies should precede any attempt at ecological explanation (Underwood and Chapman 1996; Hewitt et al. 2007). Scientific literature focused on the evaluation of variability patterns at different spatial scales in marine coastal habitats is extensive (see revision by Fraschetti et al. 2005). Nevertheless, considerable changeability in those patterns over a range of spatial scales was found (Fraschetti et al. 2005), and patterns that emerged from these studies could not necessarily be transferred to other areas.

Nowadays, monitoring of marine assemblages is a valuable tool for environmental conservation and management and has become a legal requirement in coastal regions of Europe (European Water Framework) and the USA (National Environmental Policy Act). In this context, understanding and quantifying the magnitude of the natural variability of assemblages is extremely important for implementing suitable monitoring programs and environmental impact studies (Underwood 1993; Chapman et al. 1995). Due to their high diversity, sessile nature and wide distribution, macroalgae are considered good descriptors of rocky shore assemblages, and they are widely used to characterise and monitor coastal systems (Leliaert et al. 2000; Piazzi et al. 2002) and anthropogenic disturbances (Piazzi et al. 2001; Díez et al. 2009). Therefore, macroalgae have been included as key organisms in the determination of the ecological quality status of coastal water bodies in the European water Framework Directive (Ballesteros et al. 2007; Juanes et al. 2008).

Species richness, measured as the number of different species and their abundance, is the commonest descriptor of macroalgal assemblages' structure. However, enumerating all the macroalgal species for monitoring programs is labour-intensive and requires a high level of expertise. Moreover, the number of scientists able to identify correctly macroalgae is decreasing (Brodie et al. 2009), and molecular studies have revealed cryptic diversity in macroalgae that cannot be detected by morphological observations (Lindstrom 2008; Tronholm et al. 2010). In order to reduce the time and resources consumed in identifying taxa, species can be grouped into different categories (functional groups) based on their ecological and morphological attributes (Litter and Litter 1980; Steneck and Dethier 1994; Balata et al. 2011). Although the loss of information when using this approach has been considered (Phillips et al. 1997), functional groups appear to be good descriptors of benthic communities in the previous ecological studies (Steneck and Dethier 1994; Balata et al. 2011; Rubal et al. 2011). However, the use of surrogates implies certain assumptions. The main assumption to identify an appropriate surrogate is that the relationship between the assemblage structure considering species and the surrogate is consistent in space (Colwell and Coddington 1994). These assumptions have, however, rarely been examined explicitly (Smale 2010; Rubal et al. 2011).

In the present study, intertidal macroalgal assemblages inhabiting the low-tide level of the North Portuguese coast were studied to identify their spatial pattern of variability. Specifically, we tested, by mean of a fully nested hierarchical sampling design, the following hypotheses:

1. The first hypothesis was that spatial pattern will be invariant at all the studied scales. The rejection of this hypothesis would lead to the identification of the relevant scales of spatial variance and the potential processes responsible of the variability.

2. The spatial variability pattern of the macroalgal assemblages obtained by using species will be consistent with that obtained using functional groups.

These hypotheses were tested in terms of the structure of macroalgal assemblages, considering both species and functional group approaches; response variables included the total number of taxa and biomass, as well as the biomass of the most important individually species and functional groups.

\section{Materials and methods}

\section{Study area}

This study was done along the North Portuguese coast, between latitudes $41^{\circ} 50^{\prime} 20.93^{\prime \prime}$ and $41^{\circ} 02^{\prime} 43.22^{\prime \prime} \mathrm{N}$ covering about $90 \mathrm{~km}$, during June and July 2010. The coastline of this area is largely straight and exposed to wave action with a dominant swell direction from $\mathrm{W}$ and NW and the most common wave height ranges between 1.5 and $2 \mathrm{~m}$, with maximum values around $7 \mathrm{~m}$ during winter. The coast landscape is fragmented by the presence of estuaries and varying from soft to hard substrata, resulting in many cases in a patched mixture of both substrates. The available hard substrate is a mixture of granite greywacke and schist. The tidal regime is semidiurnal, with the largest spring tides of $3.5-4.0 \mathrm{~m}$. Moreover, the studied area is subjected to a seasonal upwelling during spring and summer months that provides nutrient supply for primary producers (Lemos and Pires 2004).

This study was done on the low-tide level which is dominated by seaweeds. The most common grazers on this tidal level are Patella spp. and Paracentrotus lividus (Lamarck). Additionally, the filter feeding polychaete Sabellaria alveolata (Linnaeus) is abundant in this tidal level and can form massive reefs. The mid- and high-tide levels were not considered in the sampling because of the 
lack of macroalgae on the mid-tidal level (dominated by mussel beds) and the scarce distribution of macroalgae on the high-tidal level, dominated by barnacles with few patches of fucoids (mainly in Viana and Carreço).

\section{Sampling and processing of samples}

Samples were collected according to a structured fully hierarchical sampling design. The largest spatial scale examined was that of area, which included 2 levels: north and south, more than $30 \mathrm{~km}$ apart (Fig. 1). Within each area, 5 locations were randomly chosen (separated by less than $10 \mathrm{~km}$ ), and within each location, 3 sites (separated by $100 \mathrm{~s}$ of metres) were chosen haphazardly. At the low-tide level of each site, 3 random quadrats $(20 \times 20 \mathrm{~cm})$ separated by metres were sampled by scraping off all macroalgae.

Macroalgae were collected in a labelled plastic bag and preserved in $4 \%$ neutralized formaldehyde solution until determination. In the laboratory, all the samples were sorted, cleaned and identified to the lowest possible taxonomic level (species level in most of the cases). Then,

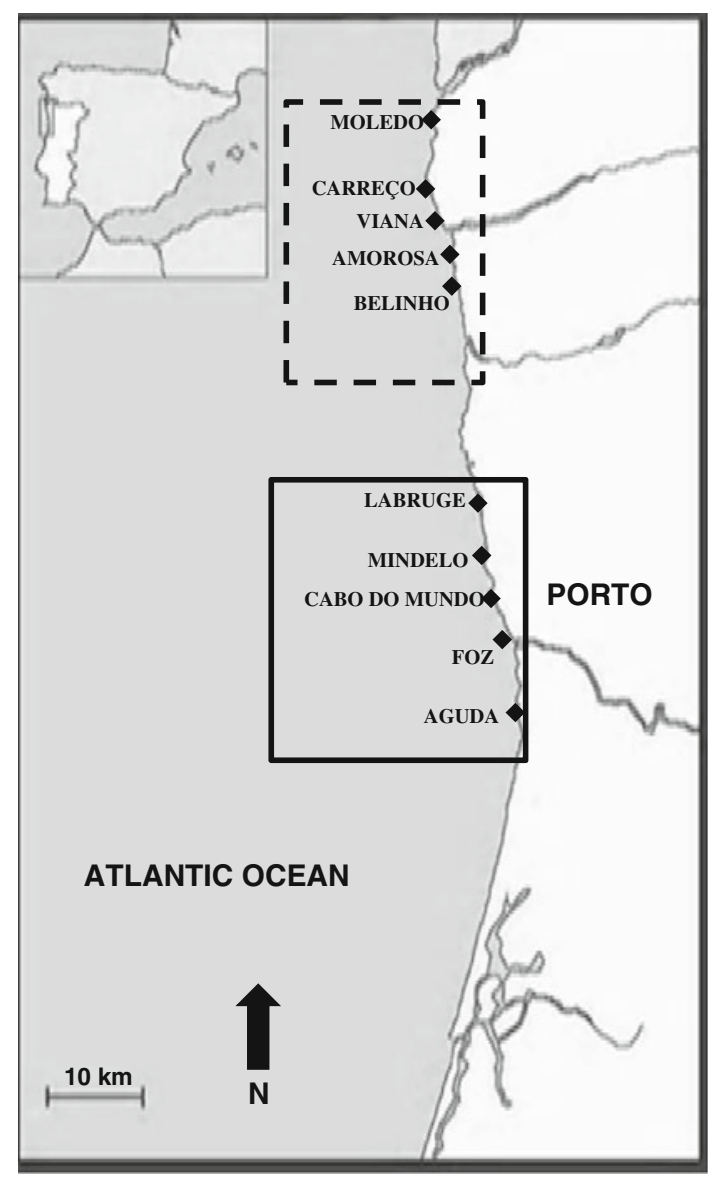

Fig. 1 Map of the Portuguese coast indicating the 10 sampling locations. The dash square includes the northern area, and the solid square includes the southern area identified species were assigned to a functional group following Steneck and Dethier (1994). Finally, the biomass of each species and functional group was calculated as its dry weight, after drying in an oven $\left(50{ }^{\circ} \mathrm{C}\right)$ for $48 \mathrm{~h}$.

Data analysis

Data were analysed using a balanced fully nested design with three random factors: area (2 levels), location (5 levels, nested in area) and site (3 levels, nested in location and area). Nested sampling designs and hierarchical analysis of variance are powerful tools to investigate patterns across scales. However, a main issue applying these methods is that the intensity of sampling and therefore the statistical power increases lower in the hierarchy (Fraschetti et al. 2005). Alternative type of analysis of variance was proposed by Underwood and Chapman (1998), but a comparative study of both methods (Fraschetti et al. 2005) justifies the use of nested analyses of variance to detect patterns at the top of hierarchy when lower level is properly replicated.

\section{Univariate analysis}

Spatial patterns of total biomass and number of taxa, as well as biomass of the most important species and functional groups, were examined by a three-way nested analysis of variance (ANOVA).

Mean squares (MS) estimates were used to assess the variance associated with each studied spatial scale. This was done by dividing the difference between the MS of the term of interest and the mean square of the term hierarchically below by the product of the levels of all terms below that of interest (Martins et al. 2008). Negative estimates of variance were removed from the analysis, and all the other values recalculated following the procedure described by Fletcher and Underwood (2002). Estimates of spatial variance were reported as percentages of actual variances to establish the magnitude of each scale contribution to patterns of distribution.

All the analyses were done on untransformed data to provide variance components comparable across all data. Prior to the analysis, Cochran's $C$ test was employed to assess homogeneity of variances. The most stringent criterion of $P<0.01$ was used to reject null hypotheses when variances were heterogeneous (Underwood 1997). All the univariate analyses were done using the GMAV5 programme (University of Sydney, Australia).

Multivariate analysis

Spatial patterns of macroalgal assemblages were examined following the same general procedure described for the univariate analysis. For this aim, a distance-based multivariable 
analysis of variance (PERMANOVA, Anderson 2001) was used. Permutations were based on a Bray-Curtis similarity matrix built from the biomass data both for species and functional groups. All the analyses were done on untransformed data (Fraschetti et al. 2005). The statistical significance of multivariate components of variance was tested using a maximum of 999 permutations under a reduced model with significance level set, a priori, at $P<0.05$.

The multivariate pseudo-variance components, which can be considered as analogues to the univariate ANOVA estimators, were used to calculate the components of variance associated with each spatial scale in a similar way to the described for the univariate analysis (Anderson et al. 2008). Negative values were set to zero following Fletcher and Underwood (2002).

Finally, to analyse the possible loss of information by using functional groups as surrogate for species, similitude between the correlation matrices based on species and functional groups was studied by the RELATE test, which were conducted at the three spatial scales (quadrat, site and location) by pooling samples to the relevant hierarchical level. All multivariate procedures were done in the Primer 6 software (Clarke and Warwick 2001) with the PERMANOVA add-on (Anderson et al. 2008).

\section{Results}

Species and functional groups diversity

We identified a total of 74 species of which only two, Ulva spp. and Porphyra spp., were not unambiguously attributed to a singular species (Table 1). In terms of biomass, Corallina officinalis Linnaeus, Chondracanthus acicularis (Roth) Fredericq and Ulva spp. were dominant along the surveyed coast; Ulva spp., Ceramium botryocarpum A.W. Griffiths ex Harvey and Osmundea pinnatifida (Hudson) Stackhouse were most common according to their frequency of occurrence.

The 74 species were assigned among a total of 7 functional groups (Table 1). In terms of biomass, the dominant functional groups were corticated, articulated calcareous and foliose. The most common functional groups were foliose, corticated and corticated filamentous.

\section{Univariate analyses}

Total biomass did not show significant variability at any of the studied spatial scales while total number of taxa only significantly varied at the scale of site (Table 2).

Estimates of components of variance, both for total biomass and total number of taxa, indicated that most variability occurred at the smallest spatial scale (among quadrats) as indicated by the large values of the estimated component of variance due to the residual (Fig. 2a). Therefore, variability decreased when wider spatial scales were considered except for total biomass that showed higher variability at the scale of area than at the scale of location (Fig. 2a).

None of the species showed significant variability at any of the studied spatial scales. All the species showed heterogeneous variances so, a more conservative $P$ value $(<0.01)$ was considered (Table 3$)$.

Independent of species identity, components of variability exhibited a similar pattern as described above for total biomass and total number of taxa with most variability occurring at the smallest spatial scale (Fig. 2b). Therefore, variability increased when the considered spatial scale decreased except for Corallina officinalis and Ulva spp. Corallina officinalis biomass showed higher variability at the scale of area than at the scale of location while Ulva spp biomass had higher variability at the scale of area and location than at the scale of site (Fig. 2b).

ANOVA was also done to compare spatial variability of the most important functional groups across different scales. Only foliose functional group varied significantly at the scale of area. However, for the rest of the studied spatial scales and functional groups, no significant variation was reported (Table 4).

Estimates of components of variance for functional groups (Fig. 2c) exhibited the same pattern described for species, with increasing variability at smaller spatial scales. However, some differences were detected among the functional groups. The articulated calcareous functional group showed lower variability at the scale of site than at the scales of area and location, whereas foliose and corticated filamentous functional groups presented higher variability at the scale of area than at the scales of location and site (Fig. 2c).

\section{Multivariate analyses}

When macroalgal biomass data were considered at species level, PERMANOVA provided evidence that assemblage structure varied significantly at all the studied spatial scales except for area (Table 5). When macroalgal biomass data were considered using functional groups, PERMANOVA analysis displayed the same results as for species-level approach with significant variability at all the studied spatial scales except for area (Table 5).

A breakdown of the components of variance indicated that variability at the smallest scale of quadrats (residual) was the major contributor to overall variability in macroalgal assemblages considering both species and functional groups (Fig. 3). Variability between sites and locations was moderate while variability between areas was negligible (Fig. 3). Therefore, when assemblages were considered at 


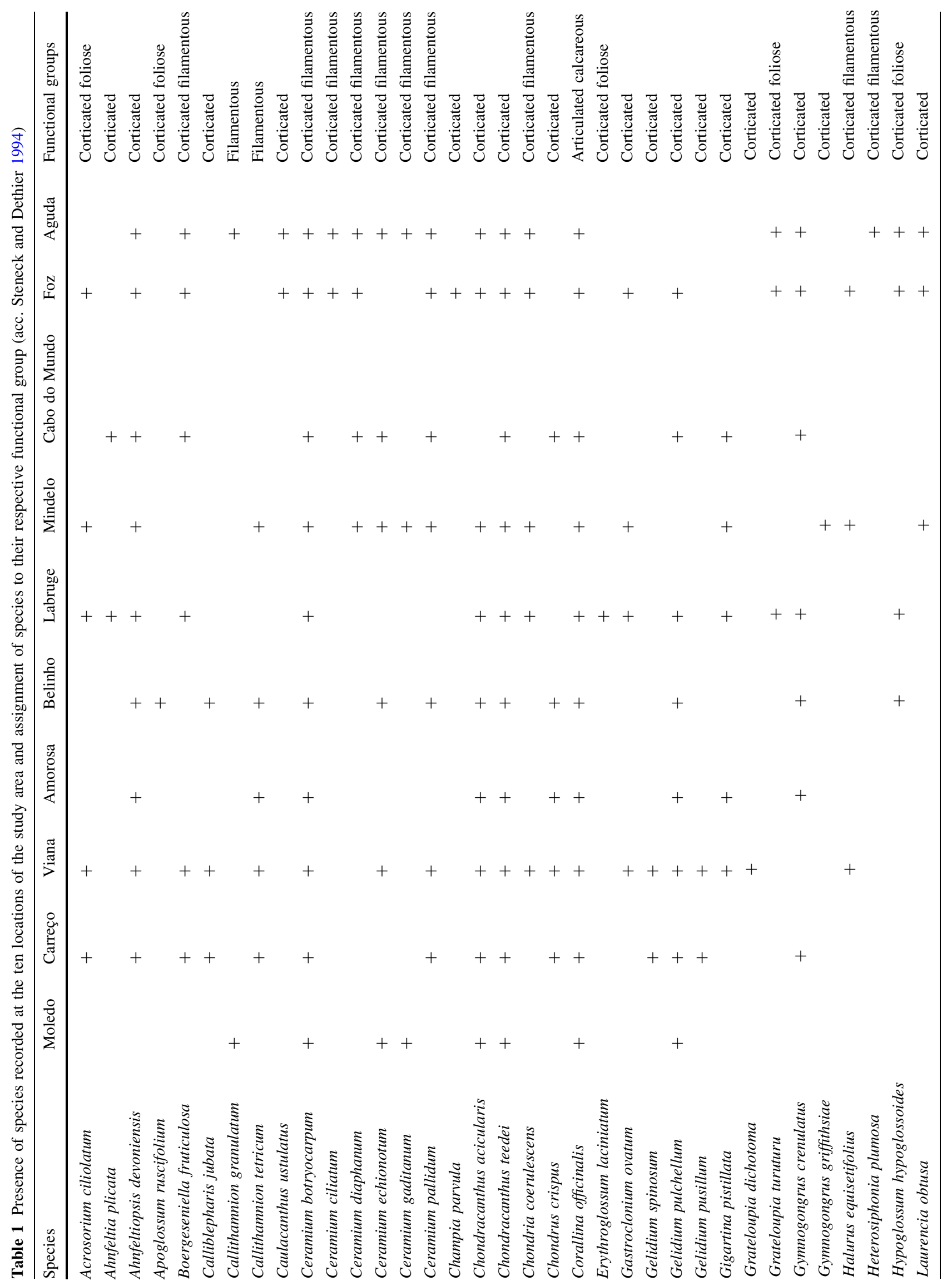




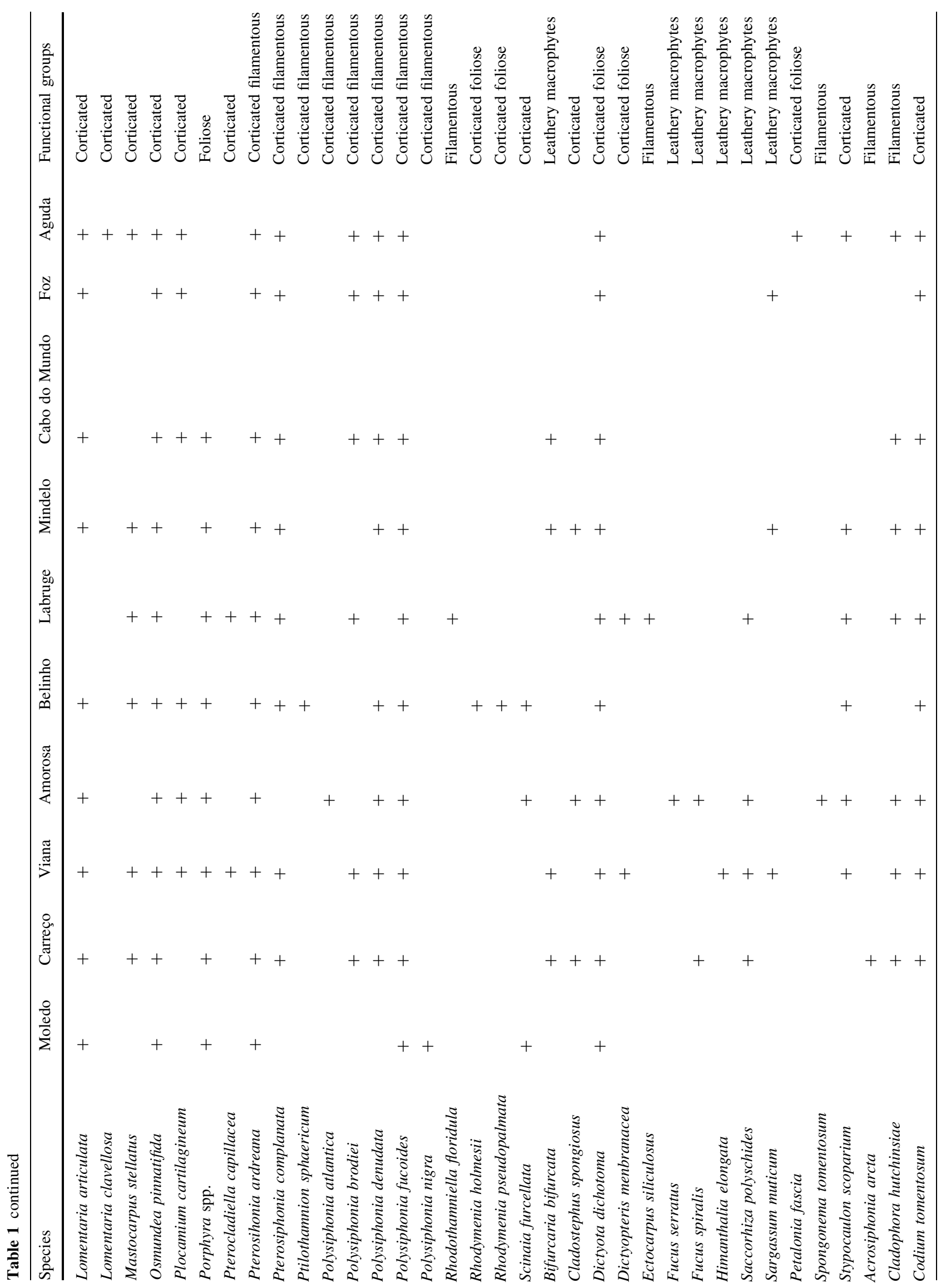




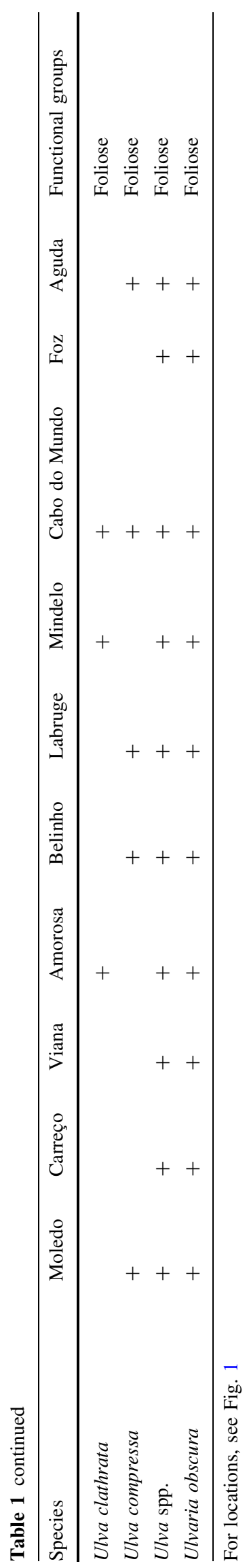

the species level, results match with those obtained at the functional group level. Finally, the RELATE test showed a high correlation between the matrices obtained from data considering species and functional groups $(r=0.76$, $P<0.001)$ at the smaller scale (quadrats). At the scale of site, the correlation was still high but a bit reduced ( $r=0.69, P<0.001$ ) while this trend became even more pronounced at the scale of location $(r=0.55, P<0.003)$. The strength of multivariate correlation between species and functional groups was generally high. However, the correlation values decreased as the spatial scale increased, showing that more information was lost using functional groups at wider spatial scales.

\section{Discussion}

Scale is one of the critical factors in ecology because our perception of most ecological variables and processes depends upon the scale at which variables are measured (Legendre et al. 1997; Martins et al. 2008). The analysis of spatial patterns is a preliminary step before testing experimental hypothesis because results of these experiments are scale dependent (Underwood and Chapman 1996; Hewitt et al. 2007).

Results of the present study indicated that most of the univariate analyses showed no significant variability at any of the studied spatial scales. Therefore, variability of the most common species, functional groups (except for the foliose group) and total biomass were invariant to spatial scale. However, the number of macroalgal taxa showed significant variability at the scale of site. In contrast with univariate results, multivariate analyses indicated that macroalgal assemblages at the species and functional group level showed significant variability at all studied spatial scales except for area.

Broitman and Kinlan (2006) proposed that lower-trophic-level species tend to be controlled by bottom-up processes (e.g. light, nutrient availability or temperature) at broad scales (100 or 1,000 s of kilometres). However, at the scale of $10 \mathrm{~s}$ of kilometres, like in our study, these processes seem to have a homogenous effect along the whole studied area except for the foliose functional group. The latter was mainly composed by species of the genus Ulva that are ephemeral, fast-growing macroalgae with a high capacity to respond to nutrient pulses (Karez et al. 2004). Due to their ecophysiological traits, the abundance of these species is very variable (Rubal et al. 2011). Therefore, the variability of this group between the two studied areas could be related to temporal changes in nutrient availability. Variations in nutrient availability should be more related to local nutrients inputs than with upwelling events, because upwelling seems to have a 
Table 2 Spatial differences in total biomass and total number of taxa at the scales of area, location and site (ANOVA; significance level $P<0.05$ )

\begin{tabular}{|c|c|c|c|c|c|c|c|}
\hline \multirow[t]{2}{*}{ Source } & \multirow[t]{2}{*}{$d f$} & \multicolumn{3}{|l|}{ Biomass } & \multicolumn{3}{|c|}{ Number of taxa } \\
\hline & & MS & $F$ & $P$ & MS & $F$ & $P$ \\
\hline Area & 1 & 737.537 & 4.27 & 0.073 & 1.600 & 0.02 & 0.894 \\
\hline Location (Re) & 8 & 172.731 & 1.11 & 0.397 & 84.167 & 2.36 & 0.057 \\
\hline Site $(\mathrm{Lo}(\mathrm{Re}))$ & 20 & 155.556 & 1.50 & 0.117 & 35.711 & 2.95 & 0.001 \\
\hline Residual & 60 & 103.991 & & & 12.111 & & \\
\hline Total & 89 & & & & & & \\
\hline Cochran's $C$-test & & $0.178^{\mathrm{ns}}$ & & & $0.095^{\mathrm{ns}}$ & & \\
\hline
\end{tabular}
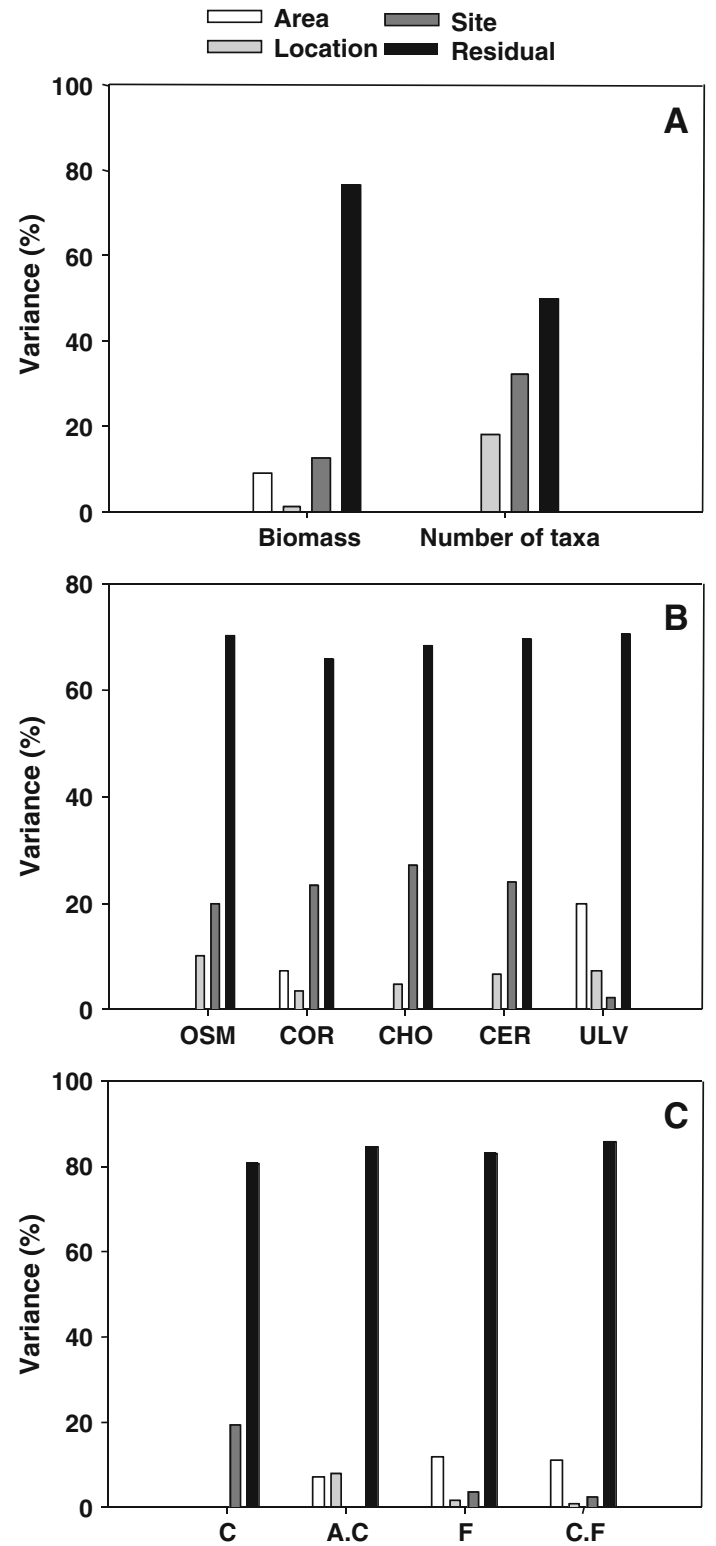

Fig. 2 Univariate estimates of variance associated with each spatial scale in percentage of contribution for: total biomass and number of taxa (a), the most important species (OSM is Osmundea pinnatifida, COR is Corallina officinalis, CHO is Chondracanthus acicularis, CER is Ceramium botryocarpum, and ULV is Ulva spp.) (b) and the most important functional groups $(\mathrm{C}$ is corticated, $\mathrm{AC}$ is articulated calcareous, $\mathrm{F}$ is foliose, and $\mathrm{CF}$ is corticated filamentous) (c) homogenous effect on the studied areas as aforementioned. However, coastal locations close to urban centres, such as Cabo do Mundo in the southern area, showed much higher nutrient values in winter $\left(5.12 \mu \mathrm{mol} \mathrm{L}^{-1}\right.$ of nitrate and $8.14 \mu \mathrm{mol} \mathrm{L} \mathrm{L}^{-1}$ of phosphate) than isolated locations in the north, such as Moledo $\left(0.21 \mu \mathrm{mol} \mathrm{L}^{-1}\right.$ of nitrate and $1.24 \mu \mathrm{mol} \mathrm{L}^{-1}$ of phosphate) (Rubal unpublished data).

At the scale of location (kilometres), however, significant variability was detected for macroalgal assemblages at the level of species and functional groups. Wave exposure is a common process responsible for variability between macroalgal assemblages at this scale (Tuya and Haroun 2006). The studied locations present a high variability in nearshore bathymetry and extent of the shore, but grade of exposure has not been measured. These two variables can play an important role in attenuating local wave power (Burrows et al. 2008) and thus affecting the structure of assemblages. Moreover, harvesting and trampling could be important processes acting at this spatial scale. Many of the studied locations such as Foz, Aguda, Amorosa and Viana are exposed to an intense seasonal trampling due to recreational activities in summer, and Araújo et al. (2009) found negative effects of trampling on macroalgal assemblages. Harvesting of invertebrates such as sea urchins is noticeable in many locations such as Viana or Belinho (personal observation). Sea urchin is one of the main grazers in the considered tidal level, and many previous studies have shown that sea urchins play a central role in shaping macroalgal communities (Paine and Vadas 1969; Palacín et al. 1998). Therefore, the elimination or reduction of sea urchins could have significant effects on macroalgal assemblages, especially due to the slow recolonization of this species after harvesting (Palacín et al. 1997).

At the scale of site (100 s of metres), significant variability was detected for the total number of species and for macroalgal assemblages, both at the level of species and functional groups. Differences in the substrate slope, preemption and grazing pressure are potential processes responsible for variability at this spatial scale. These factors have been mentioned as responsible for differences between sites in the previous studies (e.g. Benedetti-Cecchi et al. 1999, 2001). 
Table 3 Spatial differences in the biomass of the most important species: Corallina officinalis, Chondracanthus acicularis, Ulva spp., Ceramium botryocarpum and Osmundea pinnatifida at the scales of area, location and site (ANOVA; significance level $P<0.05$ )

\begin{tabular}{|c|c|c|c|c|c|c|c|c|c|c|}
\hline \multirow[t]{2}{*}{ Source } & \multicolumn{3}{|c|}{ Area $d f=1$} & \multicolumn{3}{|c|}{ Location $(\mathrm{Re}) d f=8$} & \multicolumn{3}{|c|}{ Site $(\operatorname{Lo}(\operatorname{Re})) d f=20$} & \multirow{2}{*}{$\begin{array}{l}\text { Residual } d f=60 \\
\text { MS }\end{array}$} \\
\hline & MS & $F$ & $P$ & MS & $F$ & $P$ & MS & $F$ & $P$ & \\
\hline C. officinalis ${ }^{\mathrm{a}}$ & 263.066 & 3.01 & 0.121 & 87.407 & 1.23 & 0.331 & 70.890 & 2.07 & 0.016 & 34.296 \\
\hline C. acicularis $^{\mathrm{a}}$ & 26.341 & 0.58 & 0.468 & 45.443 & 1.34 & 0.279 & 33.828 & 2.19 & 0.010 & 15.416 \\
\hline Ulva spp. ${ }^{\mathrm{a}}$ & 35.872 & 7.27 & 0.027 & 4.936 & 1.84 & 0.128 & 2.677 & 1.10 & 0.371 & 2.428 \\
\hline C. botryocarpum ${ }^{\mathrm{a}}$ & 0.028 & 0.21 & 0.660 & 0.135 & 1.56 & 0.199 & 0.086 & 2.03 & 0.018 & 0.043 \\
\hline O. pinnatifida $a^{\mathrm{a}}$ & 0.130 & 0.03 & 0.866 & 4.292 & 1.90 & 0.117 & 2.260 & 1.85 & 0.035 & 1.220 \\
\hline
\end{tabular}

a Variances heterogeneous

Table 4 Spatial differences in the biomass of the most important functional groups at the scales of area, location and site (ANOVA; significance level $P<0.05)$

\begin{tabular}{|c|c|c|c|c|c|c|c|c|c|c|}
\hline \multirow[t]{2}{*}{ Source } & \multicolumn{3}{|c|}{ Area $d f=1$} & \multicolumn{3}{|c|}{ Location $(\operatorname{Re}) d f=8$} & \multicolumn{3}{|c|}{ Site $($ Lo $(\operatorname{Re})) d f=20$} & \multirow{2}{*}{$\begin{array}{l}\text { Residual } d f=60 \\
\text { MS }\end{array}$} \\
\hline & MS & $F$ & $P$ & MS & $F$ & $P$ & MS & $F$ & $P$ & \\
\hline Corticated $^{\mathrm{a}}$ & 48.532 & 0.660 & 0.439 & 73.206 & 0.990 & 0.472 & 73.882 & 1.740 & 0.051 & 42.357 \\
\hline Articulated calcareous $^{\mathrm{a}}$ & 251.904 & 3.080 & 0.118 & 81.897 & 2.05 & 0.092 & 39.925 & 0.88 & 0.615 & 45.5386 \\
\hline Foliose & 22.851 & 5.960 & 0.041 & 3.837 & 1.14 & 0.379 & 3.359 & 1.13 & 0.343 & 2.964 \\
\hline Cochran's $C$-test & $0.323^{\mathrm{ns}}$ & & & & & & & & & \\
\hline Corticated filamentous ${ }^{a}$ & 2.346 & 6.10 & 0.039 & 0.385 & 1.07 & 0.423 & 0.360 & 1.08 & 0.391 & 0.333 \\
\hline
\end{tabular}

${ }^{a}$ Variances heterogeneous

Table 5 Spatial differences in the structure of assemblages considering both species and functional group levels at the scales of area, location and site (PERMANOVA; significance level $P<0.05$ )

\begin{tabular}{|c|c|c|c|c|c|c|c|}
\hline \multirow[t]{2}{*}{ Source } & \multirow[t]{2}{*}{$d f$} & \multicolumn{3}{|l|}{ Species } & \multicolumn{3}{|c|}{ Functional groups } \\
\hline & & MS & Pseudo- $F$ & $P$ & MS & Pseudo- $F$ & $P$ \\
\hline Area & 1 & $6,317.300$ & 0.919 & 0.538 & $4,646.800$ & 0.856 & 0.575 \\
\hline Location (Re) & 8 & $6,874.100$ & 1.625 & 0.002 & $5,428.800$ & 1.855 & 0.010 \\
\hline Site (Lo $(\operatorname{Re}))$ & 20 & $4,230.900$ & 1.691 & 0.001 & $2,927.000$ & 1.627 & 0.001 \\
\hline Residual & 60 & $2,502.400$ & & & $1,799.100$ & & \\
\hline Total & 89 & & & & & & \\
\hline
\end{tabular}

The relative importance of different spatial scales in the hierarchy varied with different species and functional groups. However, the major and consistent result was that the proportion of multivariate and univariate variance at the smallest spatial scale (among quadrats) contributed most to the total variance. Such large variance at small spatial scales (metres) has been reported in many other studies (see review by Fraschetti et al. 2005), and it seems to be a common feature of rocky intertidal assemblages. However, the small spatial scale variability observed in this study was quite large in comparison with the previous studies, suggesting the great importance of processes acting at this scale in the study region. Sedimentation, dispersal of propagules and post settlement processes such as competition, grazing and desiccation are potential factors that can explain variation on small spatial scales (Coleman 2002). Moreover, Anderson et al. (2005a) have indicated that small-scale heterogeneity of habitat, differential settlement cues or patchy disturbance and succession may explain patchiness at smaller spatial scales. Only future manipulative experiments will provide a cause effect relationship between the high small-scale variability observed and the potential processes mentioned, but small-scale heterogeneity of habitat is the process more likely to be operating in this particular system, especially because our sampling did not consider a homogeneity of the substrate.

Therefore, most of the univariate analyses supported that spatial pattern was invariant at all the studied scales except for the total number of taxa and the abundance of foliose algae at the scale of location and area respectively. 


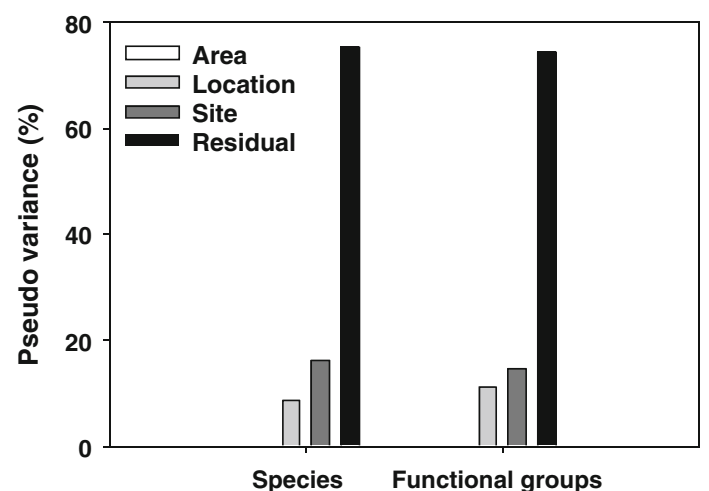

Fig. 3 Multivariate estimates of pseudo-variance associated with each spatial scale in percentage of contribution for the total assemblage considering species and functional groups

In contrast for multivariate analyses, this hypothesis was rejected except for the spatial scale of area.

Macroalgae are useful organisms to monitor the environmental quality and to detect impacts due to anthropogenic activities (Piazzi et al. 2001; Díez et al. 2009). In order to reduce time and resources for taxonomic determination of species, several surrogates have been suggested elsewhere (e.g. Phillips et al. 1997; Piazzi et al. 2001). A crucial attribute of surrogates has to be that they adequately represent pattern of spatial variability in assemblages at multiple spatial scales (Smale 2010). Our study confirmed that functional groups may be used as surrogate for monitoring studies, showing patterns remarkably consistent. Therefore, the spatial variability pattern of the macroalgal assemblages using species was consistent with that obtained using functional groups. However, analyses also showed that the consistence of the patterns decreased at wider scales. This reduction on similarity was probably related to the increase of rare species when samples were pooled at the site or location scale. While the number of functional groups is limited, and thus very stable, the number of species increased as quadrats were pooled, increasing the dissimilarity among sites or locations. Thus, despite some information was lost using functional groups, they have the ability to represent the spatial variability of macroalgal assemblages, and they could be successfully employed for monitoring programs. This result is in concordance with other studies where both approaches were used (Phillips et al. 1997; Piazzi et al. 2002; Konar and Iken 2009; Rubal et al. 2011).

Identifying relevant scales of variability is extremely important and necessary, especially at small scale, for implementing suitable monitoring programs and environmental impact studies (Underwood 1993; Chapman et al. 1995). The natural small-scale variation has been considered as a confounding factor to detect anthropogenic disturbance (Warwick 1988a, b). Therefore, if natural small-scale variation is not properly identified, changes due to impacts can be confounded with differences due to natural variability or, if the spatial scale sampled is greater than the natural variability scale, then impacts that do not exist could erroneously be detected (Coleman 2002). The use of functional groups as surrogate to investigate macroalgal assemblages seems to reduce the natural small-scale variation, and thus, it has been proposed as a solution to this problem (Konar and Iken 2009). However, in our study, the use of functional groups as a surrogate did not reduce smallscale variation compared to the species-level variation.

Therefore, functional groups can be used in future monitoring programs, in the studied area, without a significant loss of information resulting in a considerable reduction of cost and time. However, the use of functional groups does not reduce the high small-scale variability of macroalgal assemblages that can act as a confounding factor to detect anthropogenic disturbance. Moreover, the use of functional groups becomes less efficient at wide scales due to the increase of rare species. This could be a serious limitation in areas with high diversity of rare species, where the method should be tested before its application.

Acknowledgments Authors would like to thank Dr. Juan Moreira for his helpful comments that greatly improved the quality of the manuscript as well as Dr. E. Cacabelos and Marina Silva for sampling assistance. During this study, M. Rubal (SFRH/BDP/81567/2011) and P. Veiga (SFRH/BPD/81582/2011) were supported by a postdoctoral grant awarded by Fundação para a Ciência e Tecnologia (FCT, Portugal). P. Veiga was the beneficiary of a financial contribution from the AXA Research Fund. We are also grateful to Dr. I. Bartsch and two anonymous referees for all the helpful comments and suggestions, which greatly improved this paper.

\section{References}

Anderson MJ (2001) A new method for non-parametric multivariate analysis of variance. Austral Ecol 26:32-46

Anderson MJ, Connel SD, Gillanders BM, Diebel CE, Bloms WM, Saunders JE, Landers TJ (2005a) Relationships between taxonomic resolution and spatial scales of multivariate variation. J Anim Ecol 74:636-646

Anderson MJ, Diebel CE, Blom WM, Landers TJ (2005b) Consistency and variation in kelp holdfast assemblages: spatial patterns of biodiversity for the major phyla at different taxonomic resolutions. J Exp Mar Biol Ecol 320:35-56

Anderson MJ, Gorley RN, Clarke KR (2008) PERMANOVA+ for PRIMER: guide to software and statistical methods. PRIMER-E, Plymouth, UK

Araújo R, Vaselli S, Almeida M, Serrão E, Sousa-Pinto I (2009) Effects of disturbance on marginal populations: human trampling on Ascophyllum nodosum assemblages at its southern distribution limit. Mar Ecol Prog Ser 378:81-92

Balata D, Piazzi L, Rindi F (2011) Testing a new classification of morphological functional groups of marine macroalgae for the detection of responses to stress. Mar Biol 158:2459-2469

Ballesteros E, Torras X, Pinedo S, Garcia M, Mangialajo M, De Torres M (2007) A new methodology based on littoral community cartography dominated by macroalgae for the 
implementation of European water framework directive. Mar Pollut Bull 55:172-180

Benedetti-Cecchi L (2001) Variability in abundance of algae and invertebrates at different spatial scales on rocky sea shores. Mar Ecol Prog Ser 215:79-92

Benedetti-Cecchi L, Menconi M, Cinelli F (1999) Pre-emption of the substratum and the maintenance of spatial pattern on a rocky shore in the northwest Mediterranean. Mar Ecol Prog Ser 181:13-23

Benedetti-Cecchi L, Bulleri F, Acunto S, Cinelli F (2001) Scales of variation in the effects of limpets on rocky shores in the northwest Mediterranean. Mar Ecol Prog Ser 209:131-141

Brodie J, Andersen RA, Kawachi M, Millar AJK (2009) Endangered algal species and how to protect them. Phycologia 48:423-438

Broitman BR, Kinlan BP (2006) Spatial scales of benthic and pelagic producer biomass in a coastal upwelling ecosystem. Mar Ecol Prog Ser 327:15-25

Burrows MT, Harvey R, Robb L (2008) Wave exposure indices from digital coastlines and the prediction of rocky shore community structure. Mar Ecol Prog Ser 353:1-12

Burrows MT, Harvey R, Robb L, Poloczanska ES, Mieszkowska N, Moore P, Leaper R, Hawkins SJ, Benedetti-Cecchi L (2009) Spatial scales of variance in abundance of intertidal species: effects of area, dispersal mode, and trophic level. Ecology 90:1242-1254

Chapman MG, Underwood AJ, Skilleter GA (1995) Variability at different spatial scales between a subtidal assemblage exposed to the discharge of sewage and two control assemblages. J Exp Mar Biol Ecol 189:103-122

Clarke KR, Warwick RM (2001) Change in marine communities: an approach to statistical analysis and interpretation. PRIMER-E Ltd., Plymouth

Coleman MA (2002) Small-scale spatial variability in intertidal and subtidal turfing algal assemblages and the temporal generality of these patterns. J Exp Mar Biol Ecol 267:53-74

Colwell RK, Coddington JA (1994) Estimating terrestrial biodiversity through extrapolation. Phil Trans R Soc Lond B 345:101-118

Díez I, Santolaria A, Secilla A, Gorostiaga JM (2009) Recovery stages over long-term monitoring of the intertidal vegetation in the Abra de Bilbao area and on the adjacent coast (N Spain). Eur J Phycol 4:1-14

Fletcher DJ, Underwood AJ (2002) How to cope with negative estimates of components of variance in ecological field studies. J Exp Mar Biol Ecol 273:89-95

Fraschetti S, Terlizzi A, Benedetti-Cecchi L (2005) Patterns of distribution of marine assemblages from rocky shores: evidence of relevant scales of variation. Mar Ecol Prog Ser 296:13-29

Hewitt JE, Thrush SF, Dayton PK, Bonsdorff E (2007) The effect of spatial and temporal heterogeneity on the design and analysis of empirical studies of scale-dependent systems. Am Nat 169: 398-408

Juanes JA, Guinda X, Puente A, Revilla JA (2008) Macroalgae, a suitable indicator of the ecological status of coastal rocky communities in the NE Atlantic. Ecol Indic 8:351-359

Karez R, Engelbert S, Kraufvelin P, Pedersen MF, Sommer U (2004) Biomass response and changes in composition of ephemeral macroalgal assemblages along an experimental gradient of nutrient enrichment. Aquat Bot 78:103-117

Konar B, Iken K (2009) Influence of taxonomic resolution and morphological functional groups in multivariate analyses of macroalgal assemblages. Phycologia 48:24-31

Legendre P, Thrush SF, Cummings VJ, Dayton PK, Grant J, Hewitt JE, Hines AH, McArdle BH, Pridmore RD, Schneider DC, Turner SJ, Whitlatch RB, Wilkinson MR (1997) Spatial structure of bivalves in a sandflat: scale and generating processes. J Exp Mar Biol Ecol 216:99-128
Leliaert F, Anderson RJ, Bolton JJ, Coppejans E (2000) Subtidal understorey alga community in kelp beds around the Cape Peninsula (Western Cape, South Africa). Bot Mar 43:359-366

Lemos RT, Pires HO (2004) The upwelling regime off the west Portuguese coast, 1941-2000. Int J Climatol 24:511-524

Lindstrom SC (2008) Crytic diversity, biogeography and genetic variation in northeast Pacific species of Porphyra sensu lato (Bangiales, Rhodophyta). J Appl Phycol 20:951-962

Litter MM, Litter DS (1980) The evolution of thallus form and survival strategies in benthic marine macroalgae: field and laboratory tests of a functional form model. Am Nat 116:25-44

Martins GM, Thompson RC, Hawkins SJ, Neto AI, Jenkins SR (2008) Rocky intertidal community structure in oceanic islands: scales of spatial variability. Mar Ecol Prog Ser 353:15-24

Paine RT, Vadas RL (1969) The effects of grazing by sea urchins, Strongylocentrotus spp., on benthic algal populations. Limnol Oceanogr 14:710-719

Palacín C, Giribet G, Turon X (1997) Patch recolonization through migration by the echinoid Paracentrotus lividus in communities with high algal cover and low echinoid densities. Cah Biol Mar 38:267-221

Palacín C, Giribet G, Carner S, Dantart L, Turon X (1998) Low densities of sea urchins influence the structure of algal assemblages in the western Mediterranean. J Sea Res 39:281-290

Phillips JC, Kendrick GA, Lavery PS (1997) A test of a functional group approach to detecting shifts in macroalgal communities along a disturbance gradient. Mar Ecol Prog Ser 153:125-138

Piazzi L, Ceccherelli G, Cinelli F (2001) Treat to macroalgal diversity: effects of the introduced green alga Caulerpa racemosa in the Mediterranean. Mar Ecol Prog Ser 210:161-165

Piazzi L, Pardi G, Balata D, Cecchi E, Cinelli F (2002) Seasonal dynamics of a subtidal north-western Mediterranean macroalgal community in relation to depth and substrate inclination. Bot Mar 45:243-252

Rubal M, Veiga P, Vieira R, Sousa-Pinto I (2011) Seasonal patterns of tidepool macroalgal assemblages in the North of Portugal. Consistence between species and functional group approaches. J Sea Res 66:187-194

Smale DA (2010) Monitoring marine macroalgae: the influence of spatial scale on the usefulness of biodiversity surrogates. Divers Distrib 16:985-995

Steneck RL, Dethier MN (1994) A functional group approach to the structure of algal-dominated communities. Oikos 69:476-498

Tronholm A, Steen F, Tyberghein L, Leliaert F, Verbruggen H, Siguan MAR, De Clerck O (2010) Species delimitation, taxonomy and biogeography of Dictyota in Europe. J Phycol 46:1301-1321

Tuya F, Haroun RJ (2006) Spatial patterns and response to wave exposure of shallow water algal assemblages across the Canarian archipelago: a multi-scaled approach. Mar Ecol Prog Ser 311:15-28

Underwood AJ (1993) The mechanics of spatially replicated sampling programs to detect environmental impacts in a variable world. Aust J Ecol 18:99-116

Underwood AJ (1997) Experiments in ecology: their logical design and interpretation using analysis of variances. Cambridge University Press, Cambridge

Underwood AJ, Chapman MG (1996) Scales of spatial patterns of distribution of intertidal invertebrates. Oecologia 107:212-224

Underwood AJ, Chapman MG (1998) A method for analysing spatial scales of variation in composition of assemblages. Oecologia 117:570-578

Warwick RM (1988a) The level of taxonomic discrimination required to detect pollution-induced gradients in macrobenthic infaunal assemblages. Mar Ecol Prog Ser 19:259-268

Warwick RM (1988b) Analysis of community attributes of the macrobenthos of Frierfjord/Langesundfjord at taxonomic levels higher than species. Mar Ecol Prog Ser 46:167-170 